\title{
Beklenen Güven Ölçeği Türkçe Uyarlaması: Geçerlilik ve Güvenilirlik Çalışması ${ }^{1}$
} (Araştırma Makalesi)

Study of Validity and Reliability of the Expectational Trust Scale in Turkish Doi: 10.29023/alanyaakademik.807666

Ali Osman UYMAZ

Dr.Öğr. Üyesi, Alanya Alaaddin Keykubat Üniversitesi, İ̈BF, İnsan Kaynakları Bölümü aliosmanuymaz@yahoo.com

Orcid No: 0000-0002-2572-0085

Bu makaleye atıfta bulunmak için: Uymaz,A. O.,(2021). Beklenen Güven Ölçeği Türkçe Uyarlaması: Geçerlilik ve Güvenilirlik Çalışması. Alanya Akademik Bakış, 5(1), Sayfa No.45-58.

Anahtar kelimeler:

Güven

Beklenen Güven

Iyi Niyet Beklentisi

Art Niyet Beklentisi

Sosyal İlişki

Makale Geliş Tarihi:

08.10.2020

Kabul Tarihi:

25.11.2020
ÖZET

Bu çalışmanın amacı Beklenen Güven Ölçeğinin Türkçe uyarlamasını, geçerlilik ve güvenilirlik analizlerini yapmaktır. Metodolojik çalışmanın örneklemini 412 yetişkin birey oluşturmuştur. Ölçeğin Türkçeye uyarlaması; çeviri, geri çeviri, uzman görüşlerinin alınması, ölçeğin oluşturulması, ilk test ve sonrasında yeniden test verilerinin toplanmast aşamalarından oluşmuştur. Ölçek geçerlilik analizi için kapsam geçerlilik katsayısı hesaplanmış, yapı geçerliliği için doğrulayıcı faktör analizi ve madde ayırt edici gücü analizi yapılmıştır. Ölçek güvenilirliği için toplam ölçek ve alt boyutlarının iç tutarlılık göstergesi Cronbach alfa değerleri, zamana göre değişmezlik özelliği için t testi ile ilk ve yeniden test puanları üzerinden grup ve boyut düzeyinde karşılaştırma değerleri ve sınıf için korelasyon katsayıları hesaplanmıştır. Doğrulayıcı faktör analizi sonucu 15 maddeden oluşan ölçeğin tüm maddeleri korunmuştur. Ölçeğin Türkçe uyarlamasının kapsam geçerlilik katsayısı 0.98 olarak bulunmuştur. Ölçeğin Cronbach alfa değeri tüm ölçek için 0.765, beklenen art niyet boyutunun aritmetik ortalaması 3.63, standart sapması 0.65, sınıf içi korelasyon katsayısı 0.974, Cronbach alfa değeri 0.814; beklenen iyi niyet boyutunun ise aritmetik ortalaması 3.34, standart sapması 1.06, sinıf içi korelasyon katsayısı 0.927, Cronbach alfa değeri 0.725 bulunmuştur. Beklenen art niyet ve beklenen iyi niyet açısından katılımcılar değerlendirildiği zaman art niyet beklentisinin daha güçlü olduğu tespit edilmiştir. Erkek katılımcıların kadın katılımcılara açısından her iki boyut açısından istatiksel açıdan anlamlı bir fark bulunamamıştır.

\footnotetext{
${ }^{1}$ Bu makale, Alanya Alaaddin Keykubat Üniversitesi Sosyal ve Beşeri Bilimler Bilimsel Araştırma ve Yayın Etiği Kurulu'nun 16.11.2020 tarihli ve 70561447-050.01.04-E.21200 sayılı kararı ile fikri, hukuki ve telif hakları bakımından etik olarak uygun bulunmuştur.
} 
Keywords:

Trust

Expectational Trust

Expectational

Benevolence

Expectational

Malevolence

Social Relation

\begin{abstract}
This study aims to make the Turkish adaptation of the Expectational Trust Scale, and its validity, and reliability. The sample of the methodological study consisted of 412 adult individuals. The adaptation process of the scale to Turkish consists of translation, back translation, obtaining expert opinions, organizing the scale, collecting the first test data, and then collecting the retest data. The Scale has been tested with the content validity index for the scale validity; confirmatory factor analysis for construct validity; item analyses to test the scale reliability; Cronbach's alpha analysis for internal consistency of the total scale and factors; dependent samples t-test to compare the test-retest scores for time invariance; and intraclass correlation coefficient. The content validity of the Turkish version of the scale was found as 0.98. As a result of the confirmatory factor analysis, all items of the scale consisting of 15 items were preserved. The Cronbach alpha value of the scale was 0.765. For the expectational malevolence, the mean was 3.63, the standard deviation was 0.65, the intraclass correlation coefficient was 0.974, the Cronbach alpha the value was 0.814; for the expectational benevolence, the mean was 3.34, the standard deviation was 1.06, the intraclass correlation coefficient was 0.927, and the Cronbach alpha value was 0.725 . When the participants are evaluated in terms of both expectational malevolence and expectational benevolence, it has been determined that the expectational malevolence is stronger. There was no statistically significant difference between male participants and female participants in terms of both factors.
\end{abstract}

\section{GİRIŞ̧}

Güven psikolojik bir durum olarak zarar görme olasılığına rağmen bir başka grup veya kişiye karşı gösterilen itimat olarak tanımlanabilir. McAllister (1995) güveni bir kişinin bir başkasının karar, davranış ve sözlerine itimat ederek kendi karar ve davranışlarını düzenleme isteği olarak tanımlamış ve güveni iki yaklaşımla ele almıştır. Birincisi bilişsel temelli güven, güvenen kişinin güvendiğinin istikrarlı ve güvenilirlik özelliğine sahip olduğu kanısı üzerine oluşturduğu, bilgi temelli düşünsel modellerdir. Bilişsel temelli güven bilgi temelli güvendir (Lewicki \& Bunker, 1995). Güvenen kendi tecrübesi olmasa bile sahip olduğu veri üzerine güveni oluşturmuştur (Mayer, Davis, \& Schoorman, 1995). İkincisi, duygu temelli güven ise zaman için kişisel tecrübe ve karşı taraf ile bir mübadele sonucu oluşmuş güvendir. Duygusal temelli güven karşılıklı bağlılık, algılanan destek gibi olgulardan kaynaklanan güçlü, psikolojik temele sahiptir. Bilişsel temelli güven genellikle düşünsel model (Senge, 2006) düzeyindedir ve duygusal temelli güvenin de öncüsüdür (Ma, Schaubroeck, \& LeBlanc, 2020).

Güven ve güvenmeme doğrusal bir durumun iki zit kutbu olarak değil iki ayrı durum olarak değerlendirilmiştir (Lewicki, McAllister, \& Bies, 1998). Bireyde eş zamanlı olarak farklı bir tarafa karşı, farklı konular kapsamında hem güven hem de güvensizlik bulunabilir (Kramer, 1999).

Deutsch (1958) karar verme sürecinde güvenin çalışma şeklini şöyle açıklamaktadır: "Kişi, korkulanı değil, arzu ettiğini bulacağına güvendiği için açık kapıdan geçmeyi seçebilir." $\mathrm{Bu}$ diğer tarafında iyi niyetli olduğu düşünsel modelinin güçlü olmasıdır. Bu peşin güven, 
başkalarının iyi niyetli olmasını beklemektir, şüpheci olmak ise başkalarının art niyetli olduğunu veya insanların firsatçılık yapmasını beklemek veya buna inanmaktır. Bir taraf ağır basmakla birlikte bireyde hem güven hem de güvensizlik eş zamanlı olabilir (Cunha, 1985).

Art niyet beklentisi yüksek olan bireylerde olumsuz karşılık verme tutumunun ve intikam alma eğiliminin güçlü olduğu tespit edilmiştir (Eisenberger, Lynch, Aselage, \& Rohdieck, 2004). İyi niyet beklentisi yüksek bireylerin ise iletişime ve işbirliğine daha açık oldukları, yenilikçi davranışların ortaya çıkmasını sağladıkları görülmüştür (Svare, Gausdal, \& Möllering, 2020).

Literatürde güven birçok boyutta incelenmiş ve ikili ilişkilerde (Korsgaard, Brower, \& Lester, 2015), liderle mübadelede (Burke, Sims, Lazzara, \& Salas, 2007), iş takımlarında (Simon, Neuhofer, \& Egger, 2020), örgüt içinde (Liu, Zhou, Cheng, \& Zhu, 2020) güvenin önemli bir fonksiyon olduğu görülmüştür. Aynı zamanda güvenin çalışan, takım ve örgüt performansına önemli etkisi ve sonuçları olduğu tespit edilmiştir (De Jong, Dirks, \& Gillespie, 2016; Colquitt, Scott, \& LePine, 2007).

Günümüzde de hem örgüt açısından hem de birey açısından bireyin güvene yaklaşımının ve beklentisinin önceden tespit edilmesi, güvenin yönetilebilmesi ve geliştirilebilmesi için mevcut durumu ölçen bir ölçeğin olması önemlidir. Bu çalışmanın amacı Denise A. Cunha (1985) tarafından geliştirilen beklenen art niyet ve beklenen iyi niyet boyutlarından oluşan Beklenen Güven Ölçeğinin Türkçe tercümesini, Türkçeye uyarlanan ölçeğin geçerlilik ve güvenilirlik analizlerini yapmaktır.

\section{YÖNTEM}

Ölçeğin Türkçe uyarlaması sürecinde öncelikle çeviri, geri çeviri ve uygulama adımları gerçekleştirilmiştir. Orijinali İngilizce olan ölçek araştırmacı haricinde hem İngilizce hem de Türkçe bilen üç akademisyen tarafından Türkçeye tercüme edilmiştir. Türkçe üç çeviri geri çeviri için uzmanlık alanı İngilizce mütercim ve tercümanlık olan üç ayrı kişiye gönderilmiştir. İngilizce çeviriler orijinal ölçek ifadeleri ile karşılaştırılmış ve orijinal ifadelerle örtüşmekte olan maddelerden Türkçe uyarlaması oluşturulmuştur.

\subsection{Beklenen Güven Ölçeği}

Cunha tarafından geliştirilen Beklenen Güven Ölçeği toplam 15 ifadeden oluşmakta ve bireylerin karşı tarafa göstermiş oldukları bilişsel temelli güven düzeyini ölçmeyi hedeflemektedir. Ölçek iki boyuta sahiptir. Birincisi 10 ifadeye sahip Beklenen Art Niyet boyutu, ikinci boyut ise 5 ifadeye sahip Beklenen İyi Niyet boyutudur. Ölçek maddelerinde ters ifade bulunmamaktadır. Ölçek maddeleri beşli Likert $(1=$ Tamamen katılmıyorum, 5= Tamamen katılıyorum) ölçeği ile ölçülmüştür.

Veri toplama formunda katılımcıların demografik özelliklerini tespit etmeye yönelik cinsiyet, yaş, eğitim ve medeni durumları gibi sorular sorulmuştur. Katılımcılardan ilk testte ayrıca email adreslerini yazmaları istenmiştir. Bunun amacı yeniden test aşamasında aynı katılımcılara ulaşabilmek hem de çalışma sonuçlarını katılımcılarla paylaşmaktır. İlk analizde kullanılan veriler 2020 yılı Mart ayında yüz yüze toplanmıştır. Katılımcılar gönüllülük esasına göre araştırmaya katılmış ve 412 kişi destek sağlamıştır. İkinci aşama ise COVID19 tedbirleri dolayısıyla online toplanmıştır. Katılımcıların yazmış oldukları email adreslerine mesaj atılarak tekrar araştırmaya destek vermeleri istenmiştir. Yeniden test verileri 2020 yılı Temmuz ve Ağustos ayında 280 katılımcının desteği ile toplanmıştır. 
Ana kütleyi temsil eden örneklem büyüklügüünün hesaplanmasında ölçek geliştirme çalışmalarında bir madde için 10 katı olması önerilirken (Nunnally, 1978), bazı çalışmalarda ise madde sayısının örneklem büyüklüğünün belirlenmesiyle ilgili olmadığı belirtilmiştir (Clark \& Watson, 1995; Boateng, Neilands, Frongillo, Melgar-Quinonez, \& Young, 2018). Bununla birlikte ölçüm hatalarını azalttığı, faktör yüklerinin istikrarlı hale gelmesini sağladığı ve sonuçların ana kütle için genelleştirilmesine imkân verdiği için büyük örneklem tavsiye edilmektedir (Osborne \& Costello, 2004). Ana kütlenin büyük olduğu nicel çalışmalarda \%95 güven aralığı için en az 384 katılımcıdan elde edilen verilerle analiz yapılması önerilmektedir (Kurtuluş, 2011). Bu çalışma nicel, geçerlilik ve güvenilirlik çalışması kapsamında olduğu için örneklem sayısı \%95 güven aralığına göre 384 katılımcı örneklem büyüklüğü olarak belirlenmiştir.

\subsection{Katılımcıların Demografik Özellikleri}

İlk test sürecine 412 katılımcı destek vermiştir. Katılımcıların yaş aralığ 18 ila 33, ortalaması 22.6 ve standart sapması 3.71'dir; \%47'si kadın, \%53'ü erkeklerden oluşmakta; \%24'ü ön lisans, \%76'sı lisans öğrencisidir. Hali hazırda \%44'ü bir işte çalışmaktadır. Çalışmanın ikinci aşaması, yeniden teste ise 280 katılımcı destek vermiştir.

\subsection{Verilerin Analizi}

Ölçek geçerlilik ve güvenilirlik analizlerinde istatistik paket programları SPSS programı 24. ve AMOS programının 25. sürümünün; geçerlilik ve güvenilirlik analizlerinde yüzde, ortalama ve standart sapma değerleri kullanılmıştır. Ölçeğin geçerlilik ve güvenilirlik analizleri için kapsam geçerlilik, yapı geçerliliği ve güvenilirlik analizleri yapılmıştır. Analizlerde istatistiksel anlamlılık düzeyi olarak $\mathrm{p}<0.05$ kabul edilmiştir.

\subsection{Kapsam Geçerlilik}

Kapsam geçerlilik analizi, madde (Item Content Validity Indeks, I-CVI) ve ölçek düzeyinde (Scale Content Validity Indeks, S-CVI) (Rodrigues, Adachi, Beattie, \& MacDermid, 2017) olmak üzere iki aşamada hesaplanmıştır. Lawshe (1975) tarafından önerilen yönteme göre işletme anabilim dalında doktorası olan 5 akademisyen tarafından ölçeğin her maddesinin ait olduğu boyut kapsamında 'ilişkili-gerekli', 'ilişkili-yetersiz' ve 'ilişkisiz-gereksiz' olmak üzere üç kategoride değerlendirmiştir. Kapsam geçerlilik indeksinin 0.98 olduğu tespit edilmiştir. Uzman değerlendirmeleri sonucu ölçek madde düzeyinde ve ölçek düzeyinde kapsam geçerliğine sahip olduğu görülmüştür.

\subsection{Yapı Geçerliliği}

Yapı geçerliliği için ilk toplanan verilerle doğrulayıcı faktör analizi yapılmıştır. Doğrulayıcı faktör analizi uyum değerleri Tablo 1'de verilmiştir. Ölçeğin doğrulayıcı faktör analizi için yap1lan $\chi 2$ testi sonucu olarak $\chi 2=169.749, \mathrm{p}<0.000$ ve $\chi 2 /$ serbestlik derecesi $=1.997$ bulunmuştur. Diğer uyum değerleri olarak yaklaşık hataların ortalama karekökü (RMSEA) 0.0507, standartlaştırılmış ortalama hataların karekökü (SRMR) 0.034 (Browne \& Cudeck, 1992), karşılaştırmalı uyum iyiliği indeksi (CFI) 0.933, normlaştırılmış uyum indeksi (NFI) 0.876, normlaştırılmamış uyum indeksi (NNFI veya TLI) 0.917, uyum iyiliği indeksi (GFI) 0.947, düzeltilmiş uyum iyiliği indeksi (AGFI) 0.925 (Baumgartner \& Homburg, 1996) olarak bulunmuştur. Tablo 1'de de paylaşılan uyum değerleri norm değerler içinde olduğu için ölçek yapı geçerliliğine sahip olduğu görülmüştür (Byrne, 2010). 
Tablo 1. Doğrulayıcı Faktör Analizi İstatistikleri

\begin{tabular}{lc}
\hline DFA uyumluluk istatistiği & DFA uyum değerleri \\
\hline Ki-kare / p & $169.749 / .000$ \\
Ki-kare / Serbestlik derecesi & $169.749 / 85=1.997$ \\
Yaklaşık hataların ortalama karekökü (RMSEA) & 0.0507 \\
Standartlaştırılmış ortalama hataların karekökü (SRMR) & 0.034 \\
Karşılaştırmalı uyum indeksi (CFI) & 0.933 \\
Normlaşırılmamış uyum indeksi (NNFI veya TLI) & 0.917 \\
Normlaştırılmış uyum indeksi (NFI) & 0.876 \\
Uyum iyiliği indeksi (GFI) & 0.947 \\
Düzeltilmiş uyum iyiliği indeksi (AGFI) & 0.925 \\
\hline
\end{tabular}

Toplanan verilerin normal dağılıma uygunluğunu kontrol etmek için ölçek maddelerinin Skewness ve Kurtosis analizleri yapılmıştır. Tablo 2'de görüldüğü gibi maddelerin Skewness analiz değerlerinin -2.405 ile 0.317, Kurtosis analiz değerlerinin ise -1.029 ile 4.966 arasında olduğu tespit edilmiştir. Skewness ve Kurtosis değerleri -3 ile 3 arasında olduğu zaman verinin normal dağılım özelliği gösterdiğinin ifadesidir (Byrne, 2010). Skewness değerleri norm değerler içinde olmakla birlikte Kurtosis testi açısından tek 10.madde 4.966 değeri ile pozitif bir çarpıklık göstermektedir. Diğer tüm maddeler normal dağılım özelliğine sahiptir.

Madde gücü analizi için ölçek maddelerinin ait olduğu boyut ile ilişki gücünü gösteren yol katsayıları incelenmiştir. Yol katsayılarının 0.30 üzeri olması önerilmiştir (Harrington, 2009). Şekil 1 ve Tablo 2'de görüldüğü gibi maddelerin ait oldukları boyutlarla 0.391 ile 0.715 arasında değişiklik gösteren değerlerde olduğu görülmüştür. Aynı zamanda Tablo 2'de görüldüğü gibi maddelerin kritik oran değerleri $>1.96$ ve ait oldukları boyutlarla ilişkisi ve faktör yükleri istatiksel olarak anlamlıdır (Byrne, 2010). 
UYMAZ

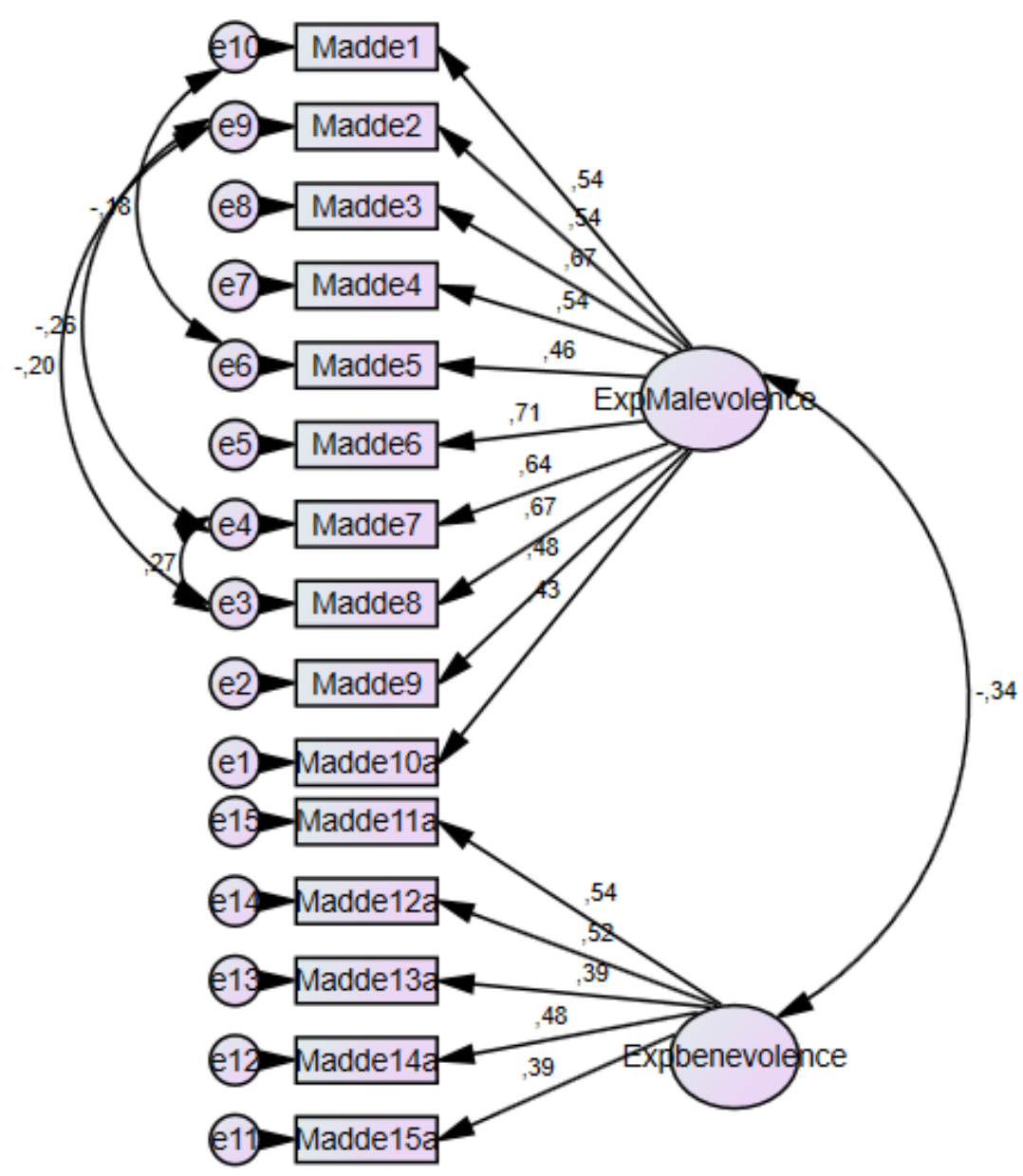

Şekil 1. Doğrulayıcı faktör analizi diyagramı

Tablo 2. Doğrulayıcı Faktör Analizi Sonucu: Ölçek Maddeleri Gücü ve Anlamlılık Düzeyi

\begin{tabular}{llcccccc}
\hline & Skewness & Kurtosis & $\begin{array}{c}\text { Standardize } \\
\text { r değeri }\end{array}$ & $\begin{array}{c}\text { Standart } \\
\text { hata }\end{array}$ & $\begin{array}{c}\text { Kritik } \\
\text { oran }\end{array}$ & $\begin{array}{c}\text { P } \\
\text { değeri }\end{array}$ \\
\hline \multirow{6}{*}{ Beklenen } & Madde10 & -2.405 & 4.966 & 0.432 & & & 0.000 \\
& Madde9 & 0.317 & -0.933 & 0.481 & 1.675 & 6.709 & 0.000 \\
& Madde8 & -1.400 & 1.972 & 0.671 & 1.526 & 7.751 & 0.000 \\
& Madde7 & -0.829 & 0.013 & 0.642 & 1.714 & 7.606 & 0.000 \\
& Madde6 & -0.629 & -0.404 & 0.715 & 1.770 & 8.018 & 0.000 \\
& Madde5 & 0.175 & -1.029 & 0.456 & 1.684 & 6.476 & 0.000 \\
& Madde4 & -0.149 & -0.420 & 0.540 & 1.445 & 7.126 & 0.000 \\
& Madde3 & -0.617 & -0.473 & 0.674 & 1.798 & 7.851 & 0.000 \\
& Madde2 & -0.348 & -0.824 & 0.543 & 1.716 & 7.026 & 0.000 \\
& Madde1 & -1.270 & 1.402 & 0.544 & 1.278 & 7.129 & 0.000 \\
\hline
\end{tabular}




\begin{tabular}{lccccccc}
\hline & & Skewness & Kurtosis & $\begin{array}{c}\text { Standardize } \\
\text { r değeri }\end{array}$ & $\begin{array}{c}\text { Standart } \\
\text { hata }\end{array}$ & $\begin{array}{c}\text { Kritik } \\
\text { oran }\end{array}$ & $\begin{array}{c}\text { P } \\
\text { değeri }\end{array}$ \\
\hline \multirow{3}{*}{ Beklenen } & Madde15 & -1.026 & 0.477 & 0.388 & & & 0.000 \\
İyi Niyet & Madde14 & -0.949 & 0.281 & 0.485 & 0.249 & 4.923 & 0.000 \\
& Madde13 & -1.588 & 2.712 & 0.391 & 0.175 & 4.482 & 0.000 \\
& Madde12 & -1.173 & 0.821 & 0.524 & 0.248 & 5.045 & 0.000 \\
& Madde11 & -1.412 & 2.066 & 0.542 & 0.213 & 5.087 & 0.000 \\
\hline
\end{tabular}

Ölçekte yer alan her maddenin ayırt edici özellik gücünü tespit etmek için ayrıca madde ayırt edici özelliği analizi yapılmıştır. Her maddenin katılımcıları ayırt etmede ne kadar yeterli olduğunu belirlemek amacıyla birinci uygulamaya katılan katılımcılar üst \%27 ile alt \%27'lik gruplar olarak ayrılmış ve madde puanları arasındaki farkın istatistiksel anlamlılığına bakılmıştır (Matlock-Hetzel, 1997). Tablo 3 'te görüldüğü gibi her maddenin yüksek derecede ayırt edici özelliğinin bulunduğu tespit edilmiştir.

Tablo 3. Ölçek Maddeleri Ayıt Edici Gücü Analizi

\begin{tabular}{lccccccc}
\hline \multicolumn{2}{c}{ Alt Grup } & \multicolumn{2}{c}{ Üst Grup } & & & \\
MADDE NO & AO & SS & AO & SS & $\begin{array}{c}\text { t Testi } \\
\text { Değeri }\end{array}$ & $\begin{array}{c}\text { Serbestlik } \\
\text { Derecesi }\end{array}$ & P Değeri \\
\hline Madde 1 & 3.21 & 0.868 & 5.00 & 0.000 & -21.729 & 219 & 0.000 \\
Madde 2 & 1.93 & 0.554 & 4.77 & 0.420 & -43.110 & 219 & 0.000 \\
Madde 3 & 2.40 & 0.666 & 5.00 & 0.000 & -41.109 & 219 & 0.000 \\
Madde 4 & 2.21 & 0.637 & 4.50 & 0.502 & -29.769 & 219 & 0.000 \\
Madde 5 & 1.35 & 0.478 & 4.38 & 0.487 & -46.724 & 219 & 0.000 \\
Madde 6 & 2.29 & 0.596 & 4.84 & 0.370 & -38.205 & 219 & 0.000 \\
Madde 8 & 2.28 & 0.679 & 4.91 & 0.288 & -37.520 & 219 & 0.000 \\
Madde 9 & 3.13 & 0.959 & 5.00 & 0.000 & -20.577 & 219 & 0.000 \\
Madde 10 & 1.54 & 0.501 & 4.44 & 0.499 & -43.197 & 219 & 0.000 \\
Madde 11 & 3.06 & 0.891 & 5.00 & 0.000 & -22.894 & 219 & 0.000 \\
Madde 12 & 2.24 & 0.605 & 4.52 & 0.502 & -30.597 & 219 & 0.000 \\
Madde 13 & 1.82 & 0.387 & 4.54 & 0.501 & -45.180 & 219 & 0.000 \\
Madde 14 & 2.30 & 0.643 & 4.59 & 0.495 & -29.621 & 219 & 0.000 \\
Madde 15 & 1.68 & 0.468 & 4.28 & 0.451 & -42.032 & 219 & 0.000 \\
\hline
\end{tabular}

\subsection{Güvenirlik}

Ölçeğin güvenilirlik özelliğine sahip olabilmesi için iç tutarlılık göstergesi Cronbach alfa değerinin 0.70’ten yukarı olması gerekir (Cronbach, 1990). Ölçeğin tamamı için Cronbach alfa değerinin 0.765 olduğu tespit edilmiştir. Beklenen art niyet boyutu için Cronbach alfa değerinin 0.814, alt maddeler arasındaki korelasyon katsayılarının 0.21 ile 0.59 arasında; beklenen iyi niyet boyutunun Cronbach alfa değeri ise 0.725 , alt maddeler arasındaki korelasyon katsayılarının 0.28 ile 0.70 arasında olduğu tespit edilmiştir. Ait oldukları boyutun diğer maddeleriyle aralarındaki korelasyon katsayısının 0.30 ve üstü toplanan verinin analize 
uygun olduğunun göstergesidir (Yaşlığlu, 2017). Her boyutun maddeleri arası korelasyon katsayılarının 0.30 yakın ve çoğunluğunun üzeri olduğu için verilerin analize uygun olduğu kabul edilmiştir. Şekil 1'de görüldüğü gibi beklenen art niyet ile beklenen iyi niyet boyutları arasındaki korelasyonun -0.34 olduğu tespit edilmiştir. Ölçeğin boyutlar arası korelasyonun düşük olması ölçeğin geçerliliği için önemli göstergedir (Cattell, 1965; Kline, 2011).

İlk ve yeniden test ile ölçeğin zamansal tutarlılığı analiz edilmektedir. Aynı örnekleme benzer şartlarda, farklı zamanlarda uygulandığında iki uygulama arasında tutarlılık bulunması gerekir (Price, 2013). Bunun için boyut ve madde düzeyinde güvenirlilik analizi yapılmıştır. Tablo 4'te görüldüğü gibi hem beklenen art niyet hem de beklenen iyi niyet boyutlarının, ilk test verileri ile yeniden test verileri üzerinden yapılan $t$ testi sonucuna göre farklı zamanlarda yapılan ölçmelerde anlamlı bir farkın olmadığı ve yüksek düzeyde benzerlik gösterdikleri görülmüştür. Bununla birlikte aynı boyut veya gruptakilerin birbirine ne kadar benzediğini açıklayan sınıf içi korelasyon (ICC) analizi yapılmıştır. 0.90 üstü sınıf içi korelasyon katsayısı ölçeğin çok iyi düzeyde güvenirliliğe sahip olduğunun ifadesidir (Liljequist, Elfving, \& Roaldsen, 2019). Tablo 4'te görülen, analiz sonuçlarına göre beklenen art niyet için 0.974, beklenen iyi niyet için 0.927 sınıf içi korelasyon katsayıları bulunmuştur. Elde edilen sonuçlara göre ölçeğin Türkçe uyarlaması güvenirlilik özelliğine sahip olduğu kabul edilmiştir.

Tablo 4. Ölçek alt boyutları ilk test ve yeniden test ortalamaları karşılaştırılması

\begin{tabular}{lcccccccccc}
\hline & \multicolumn{1}{c}{ Ilk Test } & \multicolumn{1}{c}{ Tent } \\
\hline & $\begin{array}{c}\text { Cronbach } \\
\text { Alpha }\end{array}$ & $\begin{array}{c}\text { Madde } \\
\text { Sayısı }\end{array}$ & AO & SS & AO & SS & $\begin{array}{c}\text { T testi } \\
\text { değeri }\end{array}$ & $\begin{array}{c}\text { P } \\
\text { değeri }\end{array}$ & ICC* & $\begin{array}{c}\text { P } \\
\text { değeri }\end{array}$ \\
\hline Beklenen Art Niyet & 0.824 & 10 & 3.63 & 0,65 & 3.66 & 0.70 & -0.583 & 0.691 & 0.974 & 0.000 \\
Beklenen İyi Niyet & 0.725 & 5 & 3.34 & 1.06 & 3.36 & 1.08 & -0.394 & 0.700 & 0.927 & 0.004 \\
\hline
\end{tabular}

*ICC: Sınıf içi korelasyon katsayısı (Intraclass Correlation Coefficient)

Analiz sonuçlarına göre boyutlar düzeyinde güvenilirliği görülen ölçeğin madde düzeyinde de güvenilirlik analizi yapılmıştır. Tablo 5 'te görüldüğü gibi her madde ilk test ve yeniden test puanları $\mathrm{t}$ testi ile analiz edilmiştir. 5. maddenin p değeri $0.018<0.05$, dolayısıyla iki uygulama arasında istatistiksel anlamda bir fark tespit edilmiş ve diğer maddelerde anlamlı bir fark tespit edilmemiştir. Bunun anlamı katılımcılar ilk ve yeniden testte 5. maddeye farklı cevaplar vermişlerdir, dolayısıyla 5. maddenin ölçmede tutarlılığının düşük olduğu söylenebilir. Diğer maddeler ise zamansal tutarlılı̆̆a sahiptir.

Tablo 5. Madde Düzeyinde İlk Test ve Yeniden Test Güvenirlik Analizi

\begin{tabular}{|c|c|c|c|c|c|c|c|}
\hline & \multicolumn{2}{|c|}{ İlk Test } & \multicolumn{2}{|c|}{ Yeniden Test } & \multirow{2}{*}{$\begin{array}{l}t \text { testi } \\
\text { Değeri }\end{array}$} & \multirow{2}{*}{$\begin{array}{c}\text { Serbestlik } \\
\text { Derecesi }\end{array}$} & \multirow{2}{*}{$\begin{array}{c}\mathbf{P} \\
\text { Değeri }\end{array}$} \\
\hline & AO & SS & AO & SS & & & \\
\hline Madde1 & 4.25 & 0.877 & 4.14 & 0.982 & 1.610 & 689 & 0.108 \\
\hline Madde2 & 3.46 & 1.160 & 3.54 & 1.170 & -0.841 & 689 & 0.401 \\
\hline Madde3 & 3.82 & 1.095 & 3.89 & 1.022 & -0.869 & 689 & 0.385 \\
\hline Madde4 & 3.37 & 0.997 & 3.35 & 1.078 & 0.173 & 689 & 0.863 \\
\hline Madde5 & 2.79 & 1.251 & 3.02 & 1.273 & -2.363 & 689 & 0.018 \\
\hline Madde6 & 3.71 & 1.039 & 3.65 & 1.060 & 0.701 & 689 & 0.484 \\
\hline Madde8 & 3.76 & 1.062 & 3.77 & 1.050 & -0.091 & 689 & 0.928 \\
\hline Madde9 & 4.21 & 0.921 & 4.15 & 0.887 & 0.842 & 689 & 0.400 \\
\hline
\end{tabular}




\begin{tabular}{llllllll} 
Madde10 & 2.83 & 1.220 & 3.00 & 1.176 & -1.854 & 689 & 0.064 \\
Madde11 & 4.07 & 0.872 & 4.06 & 0.828 & 0.166 & 689 & 0.868 \\
Madde12 & 3.56 & 0.994 & 3.43 & 1.014 & 1.641 & 689 & 0.101 \\
Madde13 & 3.42 & 1.126 & 3.49 & 1.120 & -0.744 & 689 & 0.457 \\
Madde14 & 3.63 & 0.990 & 3.65 & 1.044 & -0.238 & 689 & 0.812 \\
Madde15 & 3.06 & 1.106 & 3.06 & 1.082 & -0.041 & 689 & 0.968 \\
\hline
\end{tabular}

Tablo 6. Beklenen Art Niyet ile Beklenen İyi Niyet puanlarının karşılaştırılmasıı

\begin{tabular}{lcccc}
\hline & AO & SS & T testi & P \\
\hline Beklenen Art Niyet & 3.63 & 0.65 & \multirow{2}{*}{5.732} & \multirow{2}{*}{0.000} \\
Beklenen İyi Niyet & 3.34 & 1.06 & & \\
\hline
\end{tabular}

Katılımcıların beklenen art niyeti ve beklenen iyi niyeti arasında istatistiksel anlamlı fark olup olmadığg test edildiğinde Tablo 6'da görüldüğ ü gibi 0.000 düzeyinde anlamlı bir fark vardır. Katılımcılarda art niyet beklentisinin daha güçlü, iyi niyet beklentisinin ise daha zayıf olduğu tespit edilmiştir.

Tablo 7. Cinsiyete göre olumsuz ve olumlu karşılık verme norm ölçeği puanlarının karşılaștırı̀ması

\begin{tabular}{lcccccc}
\hline & \multicolumn{2}{c}{ Kadın } & Erkek & & \\
\hline & AO & SS & AO & SS & T testi & P \\
\hline Beklenen Art Niyet & 3.67 & 0.69 & 3.58 & 0.62 & 1.392 & 0.165 \\
Beklenen İyi Niyet & 3.36 & 0.66 & 3.33 & 0.64 & 0.441 & 0.659 \\
\hline
\end{tabular}

Türkçeye uyarlanan ölçekle toplanan veriler üzerinden kadın katılımcılar ile erkek katılımcılar karşılaştırılmıştır. Tablo 7'de görüldüğü gibi hem beklenen art niyet ve hem de beklenen iyi niyet açısından erkekler ile kadınlar arasında istatistiksel açıdan anlamlı bir fark bulunmamaktadır.

Tablo 8. Eğitim düzeyine göre olumsuz ve olumlu karşılık verme norm ölçeği puanlarının karş̧ılaştırılması

\begin{tabular}{lcccccc}
\hline \multicolumn{2}{c}{ Ön lisans } & \multicolumn{2}{c}{ Lisans } & & \\
\hline & AO & SS & AO & SS & T testi & P \\
\hline Beklenen Art Niyet & 3.63 & 0.65 & 3.63 & 0.67 & 0.108 & 0.914 \\
Beklenen İyi Niyet & 3.39 & 0.67 & 3.36 & 0.71 & 0.224 & 0.823 \\
\hline
\end{tabular}

Eğitim düzeyi açısından katılımcıların karşılaştırmalı analizi yapıldığı zaman ise Tablo 8'de görüldügü gibi hem beklenen art niyet ve hem de beklenen iyi niyet açısından ön lisans ve lisans öğrencileri arasında istatistiksel açıdan anlamlı bir fark bulunmamaktadır.

\section{TARTIŞMA}

Bu çalışmada Beklenen Güven Ölçeği Türkçeye uyarlanmıştır. Türk toplumunda Beklenen Art Niyet ve Beklenen İyi Niyet boyutlarından oluşan Beklenen Güveni değerlendirmek için ölçeğin geçerli ve güvenilir bir ölçek olduğu belirlenmiştir.

Kapsam geçerlilik analizi ölçek ve madde düzeyinde gerçekleştirilmiştir. Ölçeğin kapsam geçerlilik katsayısı 0.97 bulunmuştur. Doğrulayıcı faktör analizi sonucu elde edilen uyum 
değerleri $\chi 2 / \mathrm{sd}=1.997$, yaklaşık hataların ortalama karekökü (RMSEA) 0.0507, standartlaştııılmış ortalama hataların karekökü (SRMR) 0.034 (Browne \& Cudeck, 1992), karşılaştırmalı uyum iyiliği indeksi (CFI) 0.933, normlaştırılmış uyum indeksi (NFI) 0.876, normlaştırılmamış uyum indeksi (NNFI veya TLI) 0.917, uyum iyiliği indeksi (GFI) 0.947, düzeltilmiş uyum iyiliği indeksi (AGFI) 0.925 (Baumgartner \& Homburg, 1996) değerleri ölçeğin geçerliliğinin ifadesidir.

Ölçek maddelerinin ait olduğu boyut ile ilişkisinin niteliğini gösteren yol katsayılarının 0.391 ile 0.715 arasında değişmektedir. Yol katsayılarının 0.30 üzeri olması önerilmiştir (Harrington, 2009). Maddelerin birlikte kritik oranları > 1.96'nın üzerinde olması ve $p$ değerleri 0.000 düzeyinde istatistiki olarak anlamlı olması ölçeğin geçerliğinin yüksek olduğunun göstergesidir (Byrne, 2010).

Ölçeğin güvenirlik özelliği için iç tutarlılık göstergesi olan Cronbach alfa değeri tüm ölçek için 0.765 , beklenen art niyet boyutu için 0.814 , beklenen iyi niyet boyutu için ise 0.725 bulunmuştur. Değerler 0.70 'ten büyük olduğu için güvenirliliği açısından önemli bir şartı sağlamıştır (Cronbach, 1990). Ölçek maddelerinin ayrıt edici gücü analizinde ise Tablo 3 'te görüldüğü gibi ölçek maddelerinin yüksek düzeyde ayırt edici özelliğine sahip oldukları tespit edilmiştir.

Ölçeğin güvenilir ve tutarlı olduğunu test etmek amacıyla zamana göre değişmezlik analizi için katılımcılardan yeniden veri toplanmıştır. İlk ve yeniden testin puan ortalamaları arasında istatistiksel olarak anlamlı bir düzeyde fark olup olmadığına bakılmıştır. Ölçeğin ilk test ve yeniden test puanları arasındaki uyumu test etmek için hem beklenen art niyet hem de beklenen iyi niyet boyutları için sınıf içi korelasyon katsayısı hesaplanmıştır. Tablo 4'te görüldüğü gibi her iki boyutun değeri 0.90 üzeri olduğu için yüksek düzeyde uyumlu olduğu belirlenmiş̧ir. Yine Tablo 4'te görüldüğü gibi ilk ve yeniden ölçüm puanları üzerinden boyutlar düzeyinde $t$ testi yapılmıştır. $T$ testi sonuçlarına göre ilk test ile yeniden test arasında boyutlar düzeyinde istatistiksel açıdan anlamda bir fark bulunamamıştır. Analizler sonucu elde edilen değerler ölçeğin güvenilirlik açıssından istatistiksel açıdan anlamlı olduğunu göstermektedir.

Katılımcılar beklenen art niyet ve beklenen iyi niyet açısından değerlendirildiği zaman Tablo 6'da görüldüğü gibi beklenen art niyetin daha güçlü olduğu tespit edilmiştir. Erkek ve kadın katılımcılar karşılaştırıldıkları zaman Tablo 7'de görüldüğü gibi hem beklenen art niyet hem de beklenen iyi niyet boyutları açısından istatistiksel olarak anlamlı bir fark tespit edilmemiştir. Bununla birlikte hem erkeklerde hem de kadınlarda güçlü olan boyut beklenen art niyettir. Benzer sonuçlar Tablo 8 'de görüldüğü gibi ön lisans ve lisans öğrencileri karşılaştırıldığı zaman istatistiksel açıdan anlamlı bir fark bulunmamaktadır.

Art niyet beklentisi yüksek kişilerin narsist, empati eksikliği olan kişiler olduğu, makyavellist (Tortoriello, Hart, \& Breeden, 2020; Furnham, Richards, Rangel, \& Jones, 2014), olumsuz karşıllık verme tutumlarının güçlü (Eisenberger, Lynch, Aselage, \& Rohdieck, 2004) ve şiddet eğilimlerinin yüksek olduğu (Brankley \& Abrac, 2016) tespit edilmiştir. Aynı zamanda bu bireylerin istismarcı davranışlarının bulunduğu (Kiazad, Restubog, Zagenczyk, Kiewitz , \& Tang, 2010) ve iş ahlakına aykırı davranabildikleri (Carré, Jones, \& Mueller, 2020) görülmüştür.

Beklenen iyi niyetin yüksek olması ise kişiler arası ilişkilerde (Cui \& Jiao, 2019; Wang, ve diğerleri, 2018), güvenin tesis edilmesinin hızlanmasında ve örgüt iklimine ve yenilikçiliğin 54 
(Ogbeibu, Senadjki, \& Gaskin, 2018) ortaya çıkması ve gelişmesinde, hedeflenen sonuçların gerçekleştirilmesinde büyük katkılarının olduğu tespit edilmiştir.

Çalışmanın sınırlılığı açısından değerlendirildiği zaman ölçek bireylerin davranışlarından öte tutumlarını ölçmektedir. Her ne kadar tutumun mutlak davranışa dönüşeceği anlamı gelmese de geçerli ve güvenilir bir ölçekle ölçülmüş tutumun ona bağlı birçok davranışın bilinmesini ve öngörülmesini sağlayacaktır (Baysal, 2000). Bu çalışmanın sonucu Türkçe'ye uyarlanan Beklenen Güven ölçeği bireylerin tutumlarını ölçmeye ve geliştirmeye yönelik çalışmalarda kullanılabilir.

\section{KAYNAKÇA}

BAUMGARTNER, H., \& HOMBURG, C. (1996). Applications of structural equation modeling in marketing and consumer research: A review. International Journal of Research in Marketing, 13, 139-161.

BAYSAL, A. C. (2000). Tutumlar. E. Tekarslan, T. Kılınç, \& A. C. Baysal içinde, Davranışın Sosyal Psikolojisi (s. 197-236). İstanbul: İ.Ü. İşletme Fakültesi Yayınları.

BOATENG, G. O., NEILANDS, T. B., FRONGILllO, E. A., MELGAR-QUINONEZ, H. R., \& YOUNG, S. L. (2018). Best practices for developing and validating ccales for health, social, and behavioral research: A primer. Frontiers in Public Health, 6(149), 1 18 .

BRANKLEY, A. E., \& ABRAC, J. (2016). Interpersonal malevolence: Forensic applications of dark personality research. Personality and Individual Differences, 101, 469-470.

BROWNE, M. W., \& CUDECK, R. (1992). Alternative ways of assessing model fit. Sociological Methods \& Research, 21(2), 230-258.

BURKE, C. S., SIMS, D. E., LAZZARA, E. H., \& SALAS, E. (2007). Trust in leadership: A multilevel review and integration. The Leadership Quarterly, 18, 606-632.

BYRNE, B. M. (2010). Structual Equation Modeling with AMOS. New York: Routledge.

CALIENDO, M., FOSSEN, F., \& KRITIKOS, A. (2012). Trust, positive reciprocity, and negative reciprocity: Do these traits impact entrepreneurial dynamics? Journal of Economic Psychology, 33, 394-409.

CARRÉ, J. R., JONES, D. N., \& MUELLER, S. M. (2020). Perceiving opportunities for legal and illegal profit: Machiavellianism and the dark triad. Personality and Individual Differences, 162, 109942.

CATTELL, R. B. (1965). Factor analysis: An introduction to essentials I. The purpose and underlying models. Biometrics, 21(1), 190-215.

CLARK, L. A., \& WATSON, D. (1995). Constructing validity: Basic issues in objective scale development. Psychological Assessment, 7(3), 309-319.

COLQUITT, J. A., SCOTT, B. A., \& LEPINE, J. A. (2007). Trust, trustworthiness, and trust propensity: A meta-analytic test of their unique relationships with risk taking and job performance. Journal of Applied Psychology, 92, 909-927.

CRONBACH, L. J. (1990). Essentials of Psychological Testing. New York: HarperCollins. 
CUI, Y., \& JIAO, H. (2019). Organizational justice and management trustworthiness during organizational change: Interactions of benevolence, integrity, and managerial approaches. Information Processing and Management, 56, 1526-1542.

CUNHA, D. A. (1985). Interpersonal Trust as A Function of Social Orientation. Delaware: University of Delaware.

DE JONG, B. A., DIRKS, K. T., \& GILLESPIE, N. (2016). Trust and team performance: A meta-analysis of main effects, moderators, and covariates. Journal of Applied Psychology, 101, 1134-1150.

DEUTSCH, M. (1958). Trust and suspicion. Journal of Conflict Resolution, 2, 265-279.

EISENBERGER, R., LYNCH, P., ASELAGE, J., \& ROHDIECK, S. (2004). Who takes the most revenge? Individual differences in negative reciprocity norm endorsement. Personality and Social Psychology Bulletin, 30(X), 1-13.

FURNHAM, A., RICHARDS, S., RANGEL, L., \& JONES, D. N. (2014). Measuring malevolence: Quantitative issues surrounding the Dark Triad of personality. Personality and Individual Differences, 67, 114-121.

HARRINGTON, D. (2009). Confirmatory Factor Analysis. New York: Oxford University.

KIAZAD, K., RESTUBOG, S. L., ZAGENCZYK, T. J., KIEWITZ , C., \& TANG, R. L. (2010). In pursuit of power: The role of authoritarian leadership in the relationship between supervisors' Machiavellianism and subordinates' perceptions of abusive supervisory behavior. Journal of Research in Personality, 44, 512-519.

KLINE, R. B. (2011). Principles and Practice of Structural Equation Modeling. New York: The Guilford Press.

KORSGAARD, M. A., BROWER, H. H., \& LESTER, S. W. (2015). It isn't always mutual: A critical review of dyadic trust. Journal of Management, 41(1), 47-70.

KRAMER, R. M. (1999). Trust and distrust in organizations: Emerging perspectives, enduring questions. Annual Review of Psychology, 50, 569-598.

KURTULUŞ, K. (2011). Araştırma Yöntemleri. İstanbul: Türkmen Kitabevi.

LAWSHE, C. H. (1975). A quantitave approach to content validity. Personnel Psychology, $28,563-575$.

LEWICKI, R. F., \& BUNKER, B. B. (1995). Trust in relationships. Administrative Science Quarterly, 5, 583-601.

LEWICKI, R. J., MCALLISTER, D. J., \& BIES, R. J. (1998). Trust and distrust: New relationships and realities. Academy of Management Review, 23, 438-458.

LILJEQUIST, D., ELFVING, B., \& ROALDSEN, K. S. (2019). Intraclass correlation - A discussion and demonstration of basic features. Plos One, 14(7), 1-35.

LIU, S., ZHOU, Y., CHENG, Y., \& ZHU, Y. (2020). Multiple mediating effects in the relationship between employees' trust in organizational safety and safety participation behavior. Safety Science, 125, 104611. 
MA, J., SCHAUBROECK, J. M., \& LEBLANC, C. (2020, Agustos 17). Interpersonal trust in organizations. Oxford Research Encyclopedias: https://oxfordre.com/business/view/10.1093/acrefore/9780190224851.001.0001/acrefo re-9780190224851-e-167?rskey=hlEt1d\&result=1 adresinden alınd 1

MATLOCK-HETZEL, S. (1997). Basic concepts in item and test analysis. Meeting of the Southwest Educational Research Association (s. 21). San Antonio: ERIC Document: ED406441.

MAYER, R. C., DAVIS, J. H., \& SCHOORMAN, F. D. (1995). An integrative model of organizational trust. Academy of Management Review, 20, 709-734.

MCALLISTER, D. J. (1995). Affect- and cognition-based trust as foundations for interpersonal cooperation in organizations. Academy of Management Journal, 38, 2459.

NUNNALLY, J. C. (1978). Pyschometric Theory. New York: McGraw-Hill.

OGBEIBU, S., SENADJKI, A., \& GASKIN, J. (2018). The moderating effect of benevolence on the impact of organisational culture on employee creativity. Journal of Business Research, 90, 334-346.

OSBORNE, J. W., \& COSTELLO, A. B. (2004). Sample size and subject to item ratio in principal components analysis. Practical Assessment, Research \& Evaluation, 9(11), 919.

PRICE, P. C. (2013). Research Methods in Psychology. Fresno, California: The Saylor Foundation.

RODRIGUES, I. B., ADACHI, J. D., BEATTIE, K. A., \& MACDERMID, J. C. (2017). Development and validation of a new tool to measure the facilitators, barriers and preferences to exercise in people with osteoporosis. BMC Musculoskelet Disord, 18(540), 3-9. Biomedcentral . adresinden alınd1

SENGE, P. (2006). The Fifth Discipline. US: Doubleday.

SHULMAN, T. D. (2005). Biting the hand that feeds: The employee theft epidemic. West Conshohocken, PA: Infinity Publishing.

SIMON, O., NEUHOFER, B., \& EGGER, R. (2020). Human-robot interaction: Conceptualising trust in frontline teams through LEGO ${ }^{\circledR}$ Serious Play®. Tourism Management Perspectives, 35, 100692.

SVARE, H., GAUSDAL, A. H., \& MÖLLERING, G. (2020). he function of ability, benevolence, and integrity- based trust in innovation networks. Industry and Innovation, 27(6), 585-604.

TORTORIELlO, G. K., HART, W., \& BREEDEN, C. J. (2020). Of malevolence and morality: Psychopathy dimensions are conducive to helping in highly-distressing moral dilemmas. Personality and Individual Differences, 155, 109759. 
YAŞLIOĞLU, M. M. (2017). Sosyal bilimlerde faktör analizi ve geçerlilik: Keşfedici ve doğrulayıcı faktör analizlerinin kullanılması. İstanbul Üniversitesi İşletme Fakültesi Dergisi, 46, 74-85.

\section{Beklenen Art Niyet}

1 Rekabetin yüksek olduğu günümüzde insan uyanık olmalı yoksa birilerinin onu kullanması muhtemeldir.

2 İnsanların söylediklerine değil kendi çıkarlarına baktıklarına inanmak en güvenli durumdur.

3 Şaşılacak kadar çok insan acımasız ve haindir.

4 Bazı insanlar hâlihazırda sana takmıştır, diş bilemektedir.

5 'Bütün insanlar firsat bulduklarında şeytana uyarlar, ahlaksızlık yaparlar' ilkesine göre davranmak

5 en güvenilir yoldur. İnsanların dostça davranmaları bile güvenilir olmayabilir çünkü herkes esasında kendi çıkarının peşindedir.

7 Çoğu insan bencildir ve başkaları umurlarında değildir.

8 Asla güvenilmemesi gereken birçok insan var.

9 Eğer bir kişi başka bir kişiye çok güveniyorsa belasını arıyordur.

10 Tanımadığınız kişilere işiniz düştüyse temkinli olmakta fayda vardır.

Beklenen İyi Niyet

11 Yeni biriyle tanıştığım zaman genellikle bana iyi davranacağı varsayımıyla hareket ederim.

12 İnsanlara iyi niyetli davranırsan onlar da sana iyi niyetle karşıllı verecektir.

13 İnsanların çoğunluğunun başkalarının yararına olacak şekilde davranmasını beklerim.

14 İnsanların çoğunluğu özünde iyi ve naziktir.

15 Bir zanaatkâr siz onun ustalığını küçümseseniz bile size asla kazık atmaz. 